\title{
ATITUDES FRENTE À AVALIAÇÃO PSICOLÓGICA DE CANDIDATOS À OBTENÇÃO E RENOVAÇÃO DA CNH
}

\author{
Rodolfo Augusto Matteo Ambiel \\ Universidade São Francisco \\ Jocemara Ferreira Mognon \\ Universidade São Francisco \\ Fabiana Mitiko Ishizawa \\ Universidade São Francisco
}

\begin{abstract}
Resumo
O objetivo deste estudo foi verificar as atitudes acerca do processo de avaliação psicológica pericial no trânsito. Participaram da pesquisa 50 candidatos à obtenção da primeira Carteira Nacional de Habilitação $(\mathrm{CNH})$ e de renovação, que responderam a um Questionário sociodemográfico e a Escala de Atitudes frente ao Serviço de Avaliação Psicológica. Os resultados indicaram que os participantes apresentaram atitudes favoráveis à avaliação psicológica pericial e os candidatos à primeira CNH que atribuíram maior importância ao processo. Diferentemente, os candidatos com Ensino Superior foram os que atribuíram menor importância ao processo. Não foram encontradas diferenças significativas na comparação das variáveis sexo e idade. Foram encontradas correlações estatisticamente significativas e positivas entre os fatores da Escala de atitudes e às variáveis importância, eficiência e notas atribuídas ao processo. Com base nos resultados, infere-se que apesar das queixas sobre a avaliação psicológica pericial, os candidatos avaliados reconhecem a sua importância para o trânsito.
\end{abstract}

Palavras-chave: psicologia do trânsito; motoristas; avaliação psicológica.

\section{ATTITUDES TOWARD PSYCHOLOGICAL ASSESSMENT OF CANDIDATES FOR OBTAINING AND RENEWING DRIVER'S LICENSE}

\begin{abstract}
This research aimed to verify the attitudes of the traffic-psychologic evaluation process. There were 50 participants getting their first permission or renewing the license to drive. They answered to a sociodemographic questionnaire and the Attitudes towards Psychologic Evaluation Service Scale. The Results indicated that the participants had a favorable attitude towards the evaluation. The candidates for the first driving license gave importance to the process while the candidates with undergraduate education reduced its value. There were no significances differences of sex or age. There were statistically significant and positive correlations between the factors: importance, efficiency and clarification of the process. Based on the results, it was possible to infer that despite complaints about the evaluation the candidates recognize its importance for the traffic.
\end{abstract}

Keywords: traffic psychology; drivers; psychological assessment. 


\title{
ACTITUDES HACIA LA EVALUACIÓN PSICOLÓGICA DE LOS CANDIDATOS LA OBTENCIÓN Y RENOVACIÓN DE LA LICENCIA DE CONDUCIR
}

\begin{abstract}
Resumen
Esta investigación tuvo como objetivo verificar las actitudes acerca del proceso de evaluación psicológica pericial en el tránsito. Participaron de la investigación 50 candidatos a obtener su primera Licencia de conducir y renovación, respondieron a un cuestionario sociodemográfico y a la Escala de Actitudes Frente al Servicio de Evaluación Psicológica. Los resultados indicaron que los participantes presentaban actitudes favorables a la evaluación psicológica pericial, y también, que los candidatos a la primera Licencia de conducir atribuyeron mayor importancia al proceso. Al contrario, los candidatos con educación superior fueron los que atribuyeron menor importancia al proceso. No fueron encontradas diferencias significativas en la comparación de los variables sexo y edad. Fueron encontradas correlaciones estadísticamente significativas y positivas entre los factores de la Escala de actitudes y las variables importancia, eficiencia y notas atribuidas al proceso. Con base en los resultados se infiere que a pesar de las quejas sobre evaluación psicológica pericial, los candidatos evaluados reconocen su importancia.
\end{abstract}

Palabras clave: psicología del tráfico; conductores; evaluación psicológica.

\section{INTRODUÇÃO}

O processo de avaliação psicológica pode ser entendido como um método de construção de conhecimento acerca de um indivíduo, grupo ou organização e não apenas como a aplicação deliberativa de testes variados (Santos, 2011). Diante disto, Anache (2011), afirma que os testes devem ser utilizados como forma de agregar ao processo elementos e informações acerca do funcionamento psíquico do indivíduo. Urbina (2007) já destacava que primeiro é fundamental definir qual o objetivo ao se realizar uma avaliação psicológica e a escolha de instrumentos adequados para a coleta de dados.

No final da década de 1980 , os testes psicológicos passaram por duras críticas e tiveram seu uso minimizado no Brasil, principalmente por conta de produções sem qualidade editorial, estagnando o desenvolvimento da área por quase três décadas (Pasquali \& Alchieri, 2001). Segundo os autores, as consequências foram a diminuída produção de materiais brasileiros, formação acadêmica insuficiente e inúmeros processos éticos. Como relata Santos (2011), inicialmente os testes psicológicos eram utilizados no Brasil baseando-se apenas na tradução de instrumentos produzidos em outros países, sem estudos de validade e 
adaptações para a realidade brasileira, tornando-os alvos de críticas e descrédito.

Por conta de todas as críticas referentes à avaliação psicológica e principalmente, a qualidade dos testes psicológicos, foi instituído o Sistema de Avaliação de Testes Psicológicos (SATEPSI), pela resolução Conselho Federal de Psicologia - CFP n. ${ }^{\circ}$ 02/2003, composto por uma comissão de profissionais com o intuito de analisá-los sistematicamente. Vale ressaltar que, apesar de existir o SATEPSI, cabe ao psicólogo ter a capacidade técnica e crítica de analisar se determinado instrumento é adequado ou não para a utilização na situação ou indivíduo. Assim sendo, o psicólogo é o único profissional habilitado a realizar a avaliação psicológica, caracterizada por um processo técnico e científico realizado com pessoas ou grupos de pessoas, utilizando-se de diversos métodos, técnicas e testes psicológicos (Santos, 2011).

Noronha e Reppold (2010) ponderam que, apesar de passar por momentos difíceis e de descrédito, a visão acerca da avaliação psicológica e dos testes psicológicos já vinha mostrando mudanças desde o início da década de 2000. Para as autoras, o avanço da área vem ocorrendo devido ao desenvolvimento de novos estudos de construção e validação dos instrumentos, medidas como o surgimento do SATEPSI e dos eventos científicos em que a avaliação psicológica tem sido debatida. No entanto, a formação dos psicólogos, não somente no que se refere ao conhecimento de avaliação psicológica, precisa ser aperfeiçoada. As discussões e busca por melhorias na área são fundamentais para a inclusão ou manutenção da avaliação psicológica nas diversas áreas de atuação do profissional de psicologia.

Especificamente no contexto do trânsito, Bartilotti, Scopel e Gamba (2006) destacam que a avaliação psicológica possui particularidades que a diferem de outros contextos, pois para a avaliação de condutores há determinadas características e habilidades para serem analisadas, em especial, características referentes à área percepto-reacional, motora e nível mental; do equilíbrio psíquico e habilidades específicas. Segundo a 
Resolução n. 425 de 2012 do Conselho Nacional de Trânsito (Contran), a partir de março de 2015 a avaliação psicológica pericial somente deveria ser realizada por um psicólogo que tivesse o título de especialização em psicologia do trânsito. No entanto, na prática, em muitas regiões do Brasil ainda essa exigência está sendo implantada, sendo até o momento, aceito o título de perito examinador do trânsito, o qual é consentido a quem faz um curso de 180 horas.

A Psicologia do Trânsito tem como seu objeto de estudo o comportamento de motoristas (profissionais ou não), ciclistas e pedestres (Hoffman \& Cruz, 2007). Teixeira (2011) retrata que a aplicação da avaliação psicológica no contexto do trânsito brasileiro teve seu início entre 1940 a 1950, quando as autoridades decidiram que a concessão da habilitação para dirigir deveria ser conseguida após uma bateria de testes e exames.

Rozestraten (2007) destaca as principais atuações do psicólogo do trânsito, dentre elas: trabalhar com pessoas que possuem fobia de dirigir, propor intervenções com alcoolistas, desenvolver atividades e estudos com usuários de drogas, trabalhar o relacionamento da comunidade com as questões do trânsito, trabalhar junto às empresas de transporte coletivo, promover a educação no trânsito junto às escolas, auxiliar na promoção da educação ambiental e atuar após eventos traumáticos e acidentes de trânsito, promover estudos que visem melhorias nas condições ambientais no contexto do trânsito, entre outras atividades. Entretanto, apesar de tantas possibilidades de atuação para o psicólogo do trânsito no Brasil, a maioria dos profissionais da área realizam avaliações psicológicas para obtenção e renovação da Carteira Nacional de Trânsito $(\mathrm{CNH})$ em clínicas credenciadas ao Departamento de Trânsito (Detran).

É importante destacar, nessa direção, que em 1997 se deu um momento muito importante na história da psicologia do trânsito. O presidente da época, Fernando Henrique Cardoso, vetou a avaliação psicológica neste contexto, alegando que os países que combatem 
rigorosamente à violência no trânsito não adotam o exame psicológico para motoristas. Entretanto, a partir de reivindicações pelos psicólogos, sindicato, conselhos regionais e federal de psicologia, foi derrubado o projeto de lei e a avaliação voltou a ser obrigatória (Rueda, 2011). Segundo o autor, nessa época o Contran estabeleceu a resolução n. ${ }^{\circ} 80$, que dispunha sobre os procedimentos e as técnicas que poderiam ser utilizadas. Muitas críticas ainda têm sido atribuídas à avaliação psicológica para a obtenção e renovação da $\mathrm{CNH}$, com foco principal na falta de estudos sobre os construtos que precisam ser avaliados, além da falta de qualificação dos profissionais de psicologia que atuam neste contexto, principalmente, no que se refere ao desconhecimento do que determina as resoluções e sobre a elaboração de documentos psicológicos (Gouveia et al., 2002; Rueda, 2011; Silva \& Alchieri, 2007).

Outra crítica contundente à avaliação psicológica pericial para o trânsito é a falta de estudos que contribuíam na predição de certas características individuais e o envolvimento dos motoristas em multas e acidentes. Silva e Alchieri (2007) afirmam que as pesquisas sobre as evidências de validade dos instrumentos e a utilidade de testes psicológicos que avaliam a personalidade são escassas no Brasil, não justificando assim, a necessidade de avaliação da mesma para a permissão do ato de dirigir.

A esse respeito, Silva e Alchieri (2010) analisaram os resultados dos testes psicológicos de motoristas profissionais com o intuito de verificar se estes previam o envolvimento em infrações de trânsito. A pesquisa foi realizada com 68 condutores em dois momentos, na aquisição da habilitação e cinco anos na renovação da $\mathrm{CNH}$. Os resultados não mostraram diferenças significativas nos escores médios dos testes em relação às pontuações das infrações. Desta forma, os autores concluíram que altos ou baixos escores não são determinantes na ocorrência de infrações. Além disso, verificaram diversos problemas no processo de avaliação dos candidatos, principalmente no que se diz respeito à 
aplicação, correção/análise, explicitação dos resultados, armazenamento e recuperação dos testes psicológicos.

Diante dos questionamentos sobre a necessidade da avaliação psicológica no contexto do trânsito, Gouveia et al. (2002) desenvolveram uma pesquisa com 196 pessoas dentre psicólogos, estudantes de psicologia e candidatos a obtenção ou renovação da $\mathrm{CNH}$ que responderam a Escala de Atitudes frente a Avaliação Psicológica. Segundo os autores, as atitudes são definidas como uma posição das pessoas frente aos outros, a algum acontecimento ou objeto específico. $\mathrm{Na}$ pesquisa, a maioria dos participantes era do sexo feminino (68\%) e já possuía habilitação para conduzir (54\%), com idade média de 28 anos. Os resultados indicaram que, na percepção dos participantes, a avaliação psicológica não contribui para o processo de habilitação e que dificulta a obtenção da $\mathrm{CNH}$. Em contrapartida, os participantes consideraram que os testes psicológicos são o meio mais eficiente para avaliar os candidatos para a obtenção de CNH e que os candidatos que passaram pela avaliação apresentam condições de dirigir em via pública, ou seja, a avaliação psicológica é importante porque detecta se a pessoa será imprudente no trânsito.

As percepções incoerentes encontradas no estudo de Gouveia et al. (2002) levaram Lamounier e Rueda (2005) a analisar as percepções dos candidatos a $\mathrm{CNH}$ e motoristas profissionais que obrigatoriamente precisam passar por esse processo. Foram pesquisados 783 sujeitos, sendo que 401 estavam realizando a avaliação psicológica para a obtenção de CNH pela primeira vez e 382 em processo de renovação. Para tanto, utilizaram um questionário abordando se a realização da avaliação psicológica para obtenção da $\mathrm{CNH}$ é importante, se ela pode ajudar a identificar os fatores de risco para diminuir a violência no trânsito e se a avaliação psicológica deveria ser realizada com frequência. As alternativas de resposta eram "sim" ou "não". Os resultados indicaram alta ocorrência nas respostas dos dois grupos quanto às questões estudadas, no entanto, os candidatos a $\mathrm{CNH}$ consideram o processo de avaliação como mais 
importante e que deveria ser realizado com mais frequência que os de renovação. Além disso, as mulheres mostraram acreditar mais que a avaliação ajuda a identificar fatores de risco para diminuir a violência no trânsito.

Verificar a percepção dos candidatos frente ao processo de avaliação psicológica no contexto do trânsito também foi o foco da pesquisa de Rehbein e Zacharias (2012). Participaram do estudo seis candidatos à obtenção da CNH e foram realizadas entrevistas individuais e semiestruturadas. Os participantes foram questionados sobre a importância da avaliação psicológica, se ela é capaz de identificar futuros comportamentos de risco no trânsito e sobre a necessidade da sua periodicidade. Os resultados indicaram que os candidatos não sabem ao certo o que é a avaliação psicológica, apesar de a maioria reconhecer a sua importância (83\%), acreditar que ela pode contribuir na identificação de características e habilidades importantes para 0 ato de dirigir e que deveria ocorrer com maior frequência (66\%). No entanto, apenas um candidato indicou a necessidade de maior rigor no processo de avaliação psicológica.

Apesar dos estudos (Gouveia et al., 2002; Lamounier \& Rueda, 2005; Rehbein \& Zacharias, 2012) indicarem que a percepção dos candidatos à $\mathrm{CNH}$ e de renovação ser positiva quanto ao processo de avaliação psicológica, são necessários novos estudos que procurem investigar essas atitudes, uma vez que os resultados podem servir para aperfeiçoar procedimentos na prática, além de contribuir para reflexões sobre a importância atribuída à área da psicologia do trânsito e sobre o papel exercido pelo psicólogo. Nesta perspectiva, este estudo teve como objetivo verificar as atitudes frente ao processo de avaliação psicológica, apresentadas por candidatos à aquisição ou renovação da $\mathrm{CNH}$, buscando verificar possíveis diferenças na comparação das variáveis sexo, idade, escolaridade e modalidade de habilitação (primeira $\mathrm{CNH}$ ou renovação). Além disso, também se buscou verificar a relação entre as atitudes frente ao processo de avaliação psicológica e variáveis como atribuição do grau 
de importância, eficiência e a pontuação dada pelo candidato à presumida influência da avaliação psicológica pericial sobre o comportamento de dirigir.

\section{MÉTODO}

\section{Participantes}

Participaram da pesquisa 50 candidatos à aquisição ou renovação da Carteira Nacional de Habilitação (CNH) que realizaram a Avaliação Psicológica Pericial em uma clínica credenciada ao Detran, do interior do Estado de São Paulo. As idades variaram entre 18 anos e 51 anos ( $M=$ $27,62 ; D P=10,76)$, sendo $62 \%(n=31)$ do sexo masculino e $72 \%(n=36)$ estavam obtendo a primeira CNH. Quanto à escolaridade, 22\% $(n=11)$ possuíam o Ensino fundamental, $56 \%(n=28)$ o Ensino Médio e $22 \%$ $(n=11)$ o Ensino Superior.

\section{Instrumentos}

Foi aplicado um questionário de identificação desenvolvido pelos autores do estudo para a obtenção de dados sociodemográficos como idade, sexo, escolaridade, se já possui habilitação e informações sobre a participação em avaliações psicológicas periciais anteriores no trânsito (histórico de reprovações). Além disso, o questionário continha perguntas no formato de escala Likert, sobre as opiniões dos candidatos a respeito da avaliação psicológica, tais como o grau de importância atribuída ao processo (muito importante, importante e nada importante) e eficiência (nada eficiente, pouco eficiente, eficiente, muito eficiente). Por fim, era solicitada ao participante da pesquisa uma nota de 0 a 10 a fim de expressar o nível de influência presumida da avaliação psicológica pericial sobre o comportamento de dirigir.

Além disso, foi utilizada a Escala de Atitudes frente ao Serviço de Avaliação Psicológica (Gouveia et al., 2002). O instrumento possui vinte itens que abrangem atitudes frente ao serviço de avaliação psicológica, igualmente divididos em atitudes positivas e negativas, e respondidos em 
escala de cinco pontos, com pontuações tipo Likert, sendo $1=$ Discordo Totalmente e $5=$ Concordo Totalmente. $O$ instrumento aborda três fatores. O primeiro é o Processo de Avaliação, que investiga a atribuição de importância à avaliação psicológica no processo de exame das pessoas que estão pela primeira vez solicitando sua $\mathrm{CNH}$ ou procuram renová-la. Este fator engloba os itens $05,09,11,14,17,19,20$, como exemplo de item "A avaliação psicológica não contribui em nada no processo de habilitação". O segundo é Eficácia da Avaliação, que busca avaliar a opinião das pessoas sobre o quanto a avaliação psicológica é ou não eficaz e/ou válida, formado pelos itens $01,10,13,15,16,18$, como exemplo de item "Atender os critérios psicológicos leva a uma boa condução". O último fator foi nomeado como Descrédito do Profissional e reúne itens que avaliam tanto a credibilidade quanto a desconfiança sobre o quanto o processo de avaliação psicológica pericial pode ser útil na diminuição de acidentes de trânsito. É composto pelos itens 02, 03, 04, 06, 07, 08, 12, como exemplo de item "A falta de critérios na avaliação psicológica leva a acidentes".

No estudo de Gouveia et al. (2002), os autores analisaram a fidedignidade do instrumento por meio do alfa de Cronbach, ficando os resultados do fator $1(a=0,72)$, fator $2(a=0,66)$ e fator $3(a=0,28)$. Diante do baixo valor de alfa encontrado no fator 3 , os autores não o utilizaram nas análises descritivas e ressaltaram a necessidade de novos estudos que o analisassem. Dessa forma, no presente estudo também foi analisada a fidedignidade do instrumento, resultando no fator 1 ( $\mathrm{a}=$ $0,71)$, fator $2(a=0,58)$ e fator $3(a=0,22)$. 0 alfa muito baixo no fator 3 prejudica a sua fidedignidade e, assim, como no estudo original, ele também não será utilizado nas análises estatísticas do presente estudo.

\section{Considerações Éticas}

Os procedimentos realizados durante toda a pesquisa seguiram as orientações previstas na Resolução 466/2012 do CNS e na Resolução 016/2000 do Conselho Federal de Psicologia. 
Procedimento de Coleta de Dados

Após autorização da clínica credenciada pelo Detran, o projeto foi encaminhado e aprovado pelo Comitê de Ética da Universidade de filiação dos autores (CAAE 25735513.5.0000.5514). Foram agendados cinco dias para a coleta de dados, obedecendo aos horários em que normalmente acontecem os exames. Os candidatos foram convidados a participar da pesquisa após a realização da avaliação psicológica, sendo explicado os objetivos e colhidas as assinaturas no Termo de Consentimento Livre e Esclarecido. Posteriormente, os instrumentos foram aplicados de forma coletiva, sendo iniciado com o questionário sociodemográfico e, por fim, a Escala de Atitudes frente ao Serviço de Avaliação Psicológica, com o tempo de duração de aproximadamente 30 minutos.

\section{Procedimento de Análise Estatística}

Para responder aos objetivos desta pesquisa, procedeu-se com a exploração dos dados por meio do programa Statistical Package for the Social Science - SPSS, versão 20, a fim de verificar a adequação dos dados. Com relação à normalidade, os valores de assimetria (skewness) variaram de -0,207 até -0,827 e os de achatamento (kurtosis) variaram de $-0,948$ até 2,011 . Os resultados indicaram valores muitos próximos entre a média e a mediana, além disso, tanto o teste Kolmogorov-Smirnov como Shapiro Wilk mostraram valores acima de 0,05, confirmando a distribuição normal dos dados. Dada a distribuição simétrica, utilizou-se a estatística paramétrica e adotou-se o nível de significância de 0,05. Foram utilizadas estatísticas descritivas (média e desvio-padrão) e análises inferenciais (teste-t de Student para amostras independentes e a análise de variância - ANOVA one way). Para a uma investigação da magnitude do efeito, considerou-se o índice $d$ de Cohen (1988), cuja classificação segue o seguinte critério: $d=0,20$ - efeito pequeno; $d=0,50$ - efeito médio; e $d=0,80$ - efeito elevado). A fim de analisar a relação entre as variáveis, foi utilizada a correlação de Pearson. 


\section{RESULTADOS}

A seguir são apresentados os resultados obtidos pela amostra na Escala de Atitudes frente ao Serviço de Avaliação Psicológica e nas variáveis avaliadas pelo Questionário sociodemográfico. Foram realizadas análises descritivas dos instrumentos, verificando as pontuações mínimas, máximas e médias, juntamente com o desvio-padrão que são apresentados na Tabela 1.

Tabela 1. Estatísticas descritivas da Escala de Atitudes frente ao Serviço de Avaliação Psicológica e nas variáveis abordadas pelo estudo.

\begin{tabular}{|c|c|c|c|c|c|}
\hline & & Mínimo & Máximo & Média & DP \\
\hline \multirow{3}{*}{ 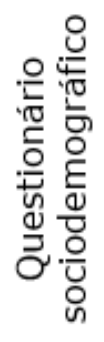 } & Grau de importância & 2,00 & 3,00 & 2,62 & 0,49 \\
\hline & Grau de eficiência & 1,00 & 3,00 & 2,26 & 0,53 \\
\hline & $\begin{array}{l}\text { Nota atribuída ao } \\
\text { processo }\end{array}$ & 7,00 & 10,00 & 9,02 & 1,09 \\
\hline \multirow{2}{*}{ 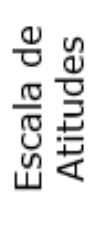 } & $\begin{array}{l}\text { Processo de } \\
\text { avaliação }\end{array}$ & 2,00 & 5,00 & 4,00 & 0,74 \\
\hline & $\begin{array}{l}\text { Eficácia da } \\
\text { avaliação }\end{array}$ & 2,50 & 5,00 & 3,97 & 0,66 \\
\hline
\end{tabular}

Observa-se que nas três primeiras variáveis descritas na Tabela 1 do questionário sociodemográfico, que os participantes atribuíram valores altos para o grau de importância e eficiência do processo, como também para nota, que confirmam a importância da avaliação psicológica. Na Escala de Atitudes frente ao Serviço de Avaliação Psicológica verifica-se também médias altas, aproximando-se dos valores máximo possíveis de serem alcançados. Assim, os resultados sugerem que a amostra investigada demonstra atitudes favoráveis ao processo e a eficácia da avaliação. 
A fim de explorar mais os dados, foi verificada a frequência nas respostas dos participantes da pesquisa em cada um dos itens da Escala de Atitudes frente ao Serviço de Avaliação Psicológica. Os resultados indicaram que a maior parte da amostra pesquisada (92\%) concorda parcial ou totalmente que "atender aos critérios psicológicos leva a uma boa condução" (item 1), 84\% concordam parcialmente e/ou totalmente que "o psicólogo é um profissional capaz de avaliá-los" (item 7), contudo, $44 \%$ concordam parcialmente e/ou totalmente que "a avaliação psicológica dificulta o processo de habilitação" (item 20). Com base nisso, verifica-se a partir das respostas que, apesar de a avaliação psicológica pericial ser importante no processo de aquisição/renovação da Carteira Nacional de Habilitação $(\mathrm{CNH})$ na visão dos avaliandos, muitos ainda acreditam que o processo pode ser dificultado pela avaliação. A análise dos itens possibilitou também perceber que nem sempre há clareza para os candidatos à $\mathrm{CNH}$ e renovação sobre os construtos que são avaliados no processo de avaliação pericial para o trânsito, como pode ser observado no item "os testes psicológicos não avaliam a imprudência", em que $48 \%$ concordam parcialmente e/ou totalmente com a afirmativa.

Foram verificadas possíveis diferenças significativas para as variáveis sociodemográficas e os fatores da Escala de Atitudes frente ao Serviço de Avaliação Psicológica, bem como as variáveis que envolviam a percepção dos candidatos quanto ao grau de importância, de eficiência e a nota geral fornecida ao processo de avaliação. Os resultados mostraram que não há diferenças estatisticamente significativas para a variável sexo nos fatores da Escala de Atitudes - processo de avaliação $(t=1,26$; $p=0,21)$, eficácia $(t=0,538 ; p=0,59)$ e nem nas variáveis grau de importância atribuída ao processo $(t=-1,84 ; p=0,72)$, grau de eficiência $(t=-0,33 ; p=0,74)$ e nota atribuída $(t=1,43 ; p=0,16)$.

Também foi comparada a idade dos participantes, mas como havia grande variedade de idades e poucos participantes em algumas delas, as idades foram reunidas em dois grupos, os participantes com idade entre 18 a 23 anos e no outro com idade de 24 ou mais. Os resultados também 
não mostraram diferenças estatisticamente significativas nos fatores da Escala de Atitudes frente ao Serviço de Avaliação Psicológica - processo de avaliação $(t=-1,40 ; p=0,17)$, eficácia $(t=-0,22, p=0,83)$ e nem nas variáveis grau de importância atribuída ao processo $(t=-1,78 ; p=0,08)$, grau de eficiência $(t=-1,39 ; p=0,17)$ e nota atribuída $(t=0,384 ; p=0,14)$. No entanto, foram encontradas diferenças significativas na comparação da escolaridade dos participantes na variável atribuição do grau de importância $[F(47,2)=3,969 ; \quad p=0,026]$, sendo confirmada pela magnitude de efeito elevada $(d=0,80)$. A prova post hoc de Tukey separou os grupos e foi possível observar que a menor média foi para os que possuem Ensino Superior.

Também foram comparadas as atitudes frente à avaliação psicológica e as demais variáveis coletadas na condição de ser candidatos à obtenção da primeira habilitação ou de renovação. Novamente não foram encontradas diferenças estatisticamente significativas nesta amostra nos fatores da Escala de Atitudes frente ao Serviço de Avaliação Psicológica - processo de avaliação $(t=-1,07 ; p=0,29)$, eficácia $(t=0,22$, $p=0,83$ ) e nem nas variáveis grau de importância atribuída ao processo $(t=1,08 ; p=0,28)$ e grau de eficiência $(t=0,21 ; p=0,83)$. No entanto, para a variável importância atribuída ao processo de avaliação psicológica houve diferença significativa $(t=2,35 ; p=0,02)$ com estimativa de magnitude de efeito moderada $(d=0,70)$ e com maior média para os candidatos à primeira habilitação. Na Tabela 2 são apresentadas as correlações obtidas entre a Escala de Atitudes frente ao Serviço de Avaliação Psicológica e os aspectos referentes à avaliação psicologia abordados no questionário sociodemográfico. 
Tabela 2. Correlação de Pearson entre os fatores da Escala de Atitudes frente ao Serviço de Avaliação Psicológica e os aspectos sobre a avaliação psicológica pericial.

\begin{tabular}{llcc}
\hline & & $\begin{array}{c}\text { Processo de } \\
\text { avaliação }\end{array}$ & $\begin{array}{c}\text { Eficácia da } \\
\text { avaliação }\end{array}$ \\
\hline Grau de Importância & $r$ & 0,277 & 0,396 \\
Grau de Eficiência & $p$ & 0,050 & 0,001 \\
Nota atribuída ao & $r$ & 0,212 & 0,329 \\
processo & $p$ & 0,130 & 0,020 \\
\hline
\end{tabular}

Na Tabela 2, é possível verificar que os resultados indicaram correlações estatisticamente significativas e positivas (Duffy, McLean, \& Monshipouri, 2011). As correlações foram de magnitude fraca entre o processo de avaliação e a variável grau de importância. Já o fator eficácia da avaliação apresentou correlações de magnitude moderada a alta com as variáveis grau de importância, grau de eficiência e a nota que expressava o quanto o candidato acredita haver relação entre o processo de avaliação psicológica pericial e o ato de dirigir.

\section{DISCUSSÃO}

O presente estudo teve como objetivo investigar as atitudes dos candidatos à obtenção a $\mathrm{CNH}$ e de renovação sobre o processo de avaliação psicológica pericial no contexto do trânsito. Buscou-se também comparar essas atitudes em relação às variáveis como sexo, idade, escolaridade, a condição se é candidato à primeira habilitação ou de renovação. Também, foi analisada a relação entre as variáveis que avaliam a percepção dos candidatos sobre a importância, eficiência e a nota dada ao processo de avaliação psicológica com os fatores da Escala de Atitudes frente ao Serviço de Avaliação Psicológica. Assim sendo, a seguir são discutidos os resultados obtidos. 
Quanto às atitudes frente à avaliação psicológica no contexto do trânsito, os participantes do presente estudo tendem a ter atitudes favoráveis, mais especificamente sobre a importância e a eficiência do processo de avaliação psicológica. Dessa forma, fica evidente a importância atribuída a avaliação psicológica no processo de exame para conseguir a permissão para dirigir e que os candidatos acreditam que os instrumentos psicológicos utilizados na avaliação são eficazes e válidos para avaliar os futuros motoristas. Esses resultados são similares a outros estudos (Gouveia et al., 2002; Lamounier \& Rueda, 2005; Rehbein \& Zacharias, 2012) que também encontraram atitudes positivas dos candidatos à primeira $\mathrm{CNH}$ e de renovação sobre o processo de avaliação psicológica para o trânsito.

Vale ressaltar que as altas médias obtidas sobre as atitudes frente à avaliação psicológica, tanto no presente estudo como nos demais (Gouveia et al., 2002; Lamounier \& Rueda, 2005; Rehbein \& Zacharias, 2012), foi de motoristas que estavam passando pelo processo de avaliação psicológica para a obtenção ou renovação da $\mathrm{CNH}$, podendo ter ocorrido algum viés da desejabilidade social. Esse conceito já descrito na literatura, segundo Furnham (1986), se refere às tendências de distorção que pode ocorre nos instrumentos de autorrelato para uma direção favorável, buscando assim o respondente negar traços e comportamentos socialmente indesejáveis. Diante disso, eles podem ter acreditado que se fossem verdadeiros em suas opiniões, poderiam ter consequências negativas como receber na avaliação final resultado de inapto no processo de avaliação psicológica, apesar de ter sido esclarecido no momento da coleta dos dados que nenhuma informação seria repassadas aos psicólogos avaliadores. Dessa forma, são necessários novos estudos com participantes que não estejam em processo de avaliação psicológica nas clínicas credenciadas ao Detran, sugerem-se como amostra, os adolescentes com idade inferior a 18 anos, os que já são motoristas, os estudantes de psicologia e de pós-graduação em psicologia do trânsito. 
$\mathrm{Na}$ análise mais aprofundada dos itens da Escala de Atitudes frente ao Serviço de Avaliação Psicológica, os resultados indicaram que apesar de a avaliação psicológica pericial ser considerada importante pelos candidatos no processo de aquisição/renovação da $\mathrm{CNH}$, muitos avaliandos ainda acreditam que o processo pode ser dificultado pela avaliação. Também foi possível perceber que nem sempre há clareza para os candidatos à $\mathrm{CNH}$ e de renovação sobre os construtos que são avaliados no processo de avaliação pericial para o trânsito. Esses achados encontram semelhanças com outros estudos, como na pesquisa de Gouveia et al. (2002), na qual os autores também observaram a existência de ambiguidade, em que os usuários, apesar de acreditarem que a avaliação fosse algo eficaz, acreditam que ela é dispensável, pois, torna o processo demorado e oneroso. Rehbein e Zacharias (2012) também encontraram que apesar de os candidatos reconhecerem a importância na avaliação psicológica e que ela pode contribuir na identificação de características e habilidades importantes para o ato de dirigir, eles não sabem ao certo o que é a avaliação psicológica.

Uma hipótese para essa ambivalência sobre o processo de avaliação psicológica talvez seja que as pessoas consideram a sua importância na tentativa de diminuição de acidentes e da violência no trânsito. No entanto, o desconhecimento sobre as variáveis e características que são avaliadas de fato, o despreparo de muitos profissionais, o uso por muitos deles de forma errônea dos testes psicológicos, o desconhecimento sobre as resoluções e laudos psicológicos estão há muitos anos prejudicando a área da avaliação psicológica pericial para o trânsito (Gouveia et al., 2002; Silva \& Alchieri, 2010).

Além dessas problemáticas, a área de psicologia do trânsito no Brasil praticamente continua estagnada, são poucos os estudos que utilizaram amostras diversificadas de motoristas na busca de evidências de validade nos instrumentos aprovados pelo SATEPSI e que são utilizados na avaliação para o trânsito, como atenção, memória e personalidade. Além disso, faltam estudos que evidenciem que esses 
construtos de fato estão relacionados com multas e acidentes de trânsito (Silva \& Alchieri, 2007), também é importante que os psicólogos especialistas em trânsito procurem explorar outras áreas de atuação importantes já destacadas por Rozestraten (2007), dentre elas, promover a educação no trânsito junto às escolas e universidade, nas empresas de transporte coletivo e propor intervenções com alcoolistas e usuários de drogas. Outras iniciativas que precisam se multiplicar pelo Brasil é o projeto proposto por Castilho, Zamprogno, Morais, Penha e Nascimento (2015) de oferecer atendimentos psicológicos individuais, grupos de orientação e de acolhimento às vítimas de acidentes de trânsito.

Este estudo buscou analisar se variáveis sociodemográficas poderiam ocasionar possíveis diferenças nas percepções e atitudes dos candidatos sobre a avaliação psicológica. Entretanto, os resultados indicaram não haver diferenças estatisticamente significativas para as variáveis sexo e idade. Já os candidatos à primeira habilitação atribuem maior importância à avaliação psicológica pericial que os de renovação. No estudo de Lamounier e Rueda (2005), também foram encontradas diferenças significativas indicando atitudes mais positivas dos candidatos à $\mathrm{CNH}$, bem como elas foram encontradas para as mulheres. No presente estudo, foram encontradas diferenças estaticamente significativas para escolaridade, em que os candidatos com ensino superior declararam dar menos importância para a avaliação psicológica. Na literatura, não foram encontrados dados comparativos para discutir esse achado. No entanto, infere-se que os candidatos com maior escolaridade tenham atitudes menos favoráveis a como o processo de avaliação psicológica é conduzido pelos psicólogos.

No que se refere às correlações encontradas entre a Escala de Atitudes frente ao Serviço de Avaliação Psicológica e os aspectos abordados no questionário de identificação, dentre eles grau de importância, eficiência e a nota atribuída ao processo, elas mostraram-se positivas e significativas. Assim, nota-se que os candidatos à obtenção e renovação da $\mathrm{CNH}$ que atribuíram ao processo de avaliação psicológica 
importância, eficiência e notas altas tenderam a apresentar também atitudes mais positivas frente ao processo de avaliação e a eficácia da avaliação. Tais achados são congruentes com os resultados discutidos sobre os outros resultados deste estudo e esperados, uma vez que as variáveis apresentam especificidades muito semelhantes.

Quanto às limitações da pesquisa, está o tamanho da amostra reduzido, a realização da coleta de dados em uma única clínica de avaliação psicologia pericial, o que reforça o fato de ser um estudo de cunho exploratório, sendo necessário o desenvolvimento de novos estudos com uma amostra maior, em mais clínicas credenciadas ao DETRAN e de diferentes regiões do Brasil. Como sugestão de pesquisa, poderia se estabelecer uma relação entre os fatores da Escala de Atitudes frente à avaliação psicológica e o resultado final da avaliação psicológica pericial, ou seja, a comparação dos dados obtidos no instrumento com a decisão final do psicólogo (apto/inapto temporário/inapto), a fim de comparar se candidatos com atitudes mais positivas frente à avaliação psicológica tendem a apresentar resultados mais satisfatórios no processo.

Espera-se que os achados deste estudo além de documentarem as atitudes dos candidatos frente à avaliação psicológica, também proporcionem reflexões sobre a atuação dos psicólogos que realizam as avaliações psicológicas no contexto do trânsito. Sabe-se que na prática são inúmeros os problemas enfrentados, mas com a busca constante por atualização e a ética dos profissionais é possível de fortalecer a área da psicologia, especificamente a psicologia do trânsito. Vale a ressalva, que o primeiro e às vezes o único contato com a psicologia para muitas pessoas, acontece no momento da avaliação psicológica pericial. Assim, há uma responsabilidade do psicólogo que efetua a avaliação psicológica com o seu trabalho e com toda a classe de profissionais da psicologia. 


\section{REFERÊNCIAS}

Anache, A. A. (2011). Notas introdutórias sobre os critérios de validação da avaliação psicológica na perspectiva dos Direitos Humanos. Ano da Avaliação Psicológica: Textos Geradores do Conselho Federal de Psicologia. Recuperado

em http://www.pol.org.br/pol/cms/pol/publicacoes/publicacoesDocument os/ anodaavaliacaopsicologica prop8.pdf

Bartilotti, C., Scopel, E. J., \& Gamba, P. C. Avaliação Psicológica de condutores de veículos terrestres no Brasil. Ano da Avaliação Psicológica: Textos Geradores do Conselho Federal de Psicologia. Recuperado em http://www.pol.org.br/pol/cms/pol/publicacoes/publicacoesDocument os/anodaavaliacaopsicologica_prop8.pdf

Castilho, J. D., Zambrogno, L. B., Morais, R. A., Penha, P. P. L., \& Nascimento, A. S. (2015). Atendimento e Reintegração Psicossocial às Vítimas de Acidentes de Trânsito: relatos de uma experiência. ABRAMET - Associação Brasileira de Medicina de Tráfego, 32(1), 52-57.

Conselho Federal de Psicologia (2003). Resolução no 002/2003. Recuperado em http://www.pol.org.br/legislacao/pdf/resolucao2003_2.pdf

Duffy, S. P., McLean, S. L., \& Monshipouri, M. (2011). Pearson's r correlation. Recuperado em http://faculty.quinnipiac. edu/ libarts/polsci/Statistics.html.

Furnham, A. (1986). Response bias, social desirability and dissimulation. Personality and Individual Differences, 7, 385- 400. doi: 10.1016/0191-8869(86)90014-0.

Gouveia, V. V., Silva, D. V., Silva, M. P. V., Andrade, M. W. C. L., Filho Silva, B. S., \& Costa, D. M. F. (2002). Atitudes frente à avaliação psicológica para condutores: perspectivas de técnicos, estudante de psicologia e usuários. Psicologia Ciência e Profissão, 22(2), 50-59. doi: 10.1590/S141498932002000200007

Hoffmann R. J. A., \& Cruz, R. M. (2007). Síntese Histórica da Psicologia do Trânsito no Brasil. In M. H. Hoffmann, R. M., Cruz, \& J. C. Alchieri (Eds). Comportamento Humano no Trânsito (pp.15-17). São Paulo: Casa do Psicólogo.

Lamounier, R., \& Rueda, F. J. M. (2005). Avaliação psicológica no trânsito: perspectiva dos motoristas. PSIC - Revista de Psicologia da Vetor Editora, $6(1), 35-42$.

Noronha, A. P. P., \& Reppold, C. (2010). Considerações sobre a avaliação psicológica no Brasil. Psicologia: Ciência e Profissão, 30, 192-201. doi: 10.1590/S1414-98932010000500009. 
Pasquali, L., \& Alchieri, J. C. (2001). Os testes psicológicos no Brasil. In L. Pasquali (Ed.), Técnicas de exame psicológico - TEP (pp. 195-211). São Paulo: Casa do Psicólogo.

Rehbein, R. M., \& Zacharias, D. G. (2012). A percepção dos candidatos a carteira nacional de habilitação a respeito da avaliação psicológica no trânsito. In $\mathrm{R}$. B. F. Silva \& S. V. C. Areosa (Eds), Avaliação Psicológica: Desafios e possibilidades para a psicologia contemporânea (pp. 24-30). Santa Cruz do Sul: EDUNISC.

Resolução do Conselho Nacional de Trânsito - CONTRAN n. 0 425/2012, dispõe sobre a avaliação psicológica e o credenciamento dos psicólogos. Recuperado em http://www.denatran.gov.br/download/Resolucoes/(Resolu\%C3\%A7\%C3\% A30\%20425.-1).pdf

Rozestraten, R. J. A. (2007). Psicologia do trânsito: conceitos e processos básicos. São Paulo: EPU.

Rueda, F. J. M. (2011). Psicologia do trânsito ou avaliação psicológica no trânsito: faz-se distinção no Brasil? Ano da Avaliação Psicológica: Textos Geradores do Conselho Federal de Psicologia. Recuperado em http://www.pol.org.br/pol/cms/pol/publicacoes/publicacoesDocumentos/ano daavaliacaopsicologica_prop8.pdf.

Santos, A. A. A. (2011). O possível e o necessário no processo de avaliação psicológica. Ano da Avaliação Psicológica: Textos Geradores do Conselho Federal de Psicologia. Recuperado em http://www.pol.org.br/pol/cms/pol/publicacoes/publicacoesDocumentos/ano daavaliacaopsicologica_prop8.pdf.

Silva, F. H. V. C., \& Alchieri, J. C. (2007). Avaliação psicológica da personalidade de condutores: uma revisão de literatura. PSICO-USF, 12(2), 189-196. doi: 10.1590/S1413-82712007000200007.

Silva, F. H. V. C., \& Alchieri, J. C. (2010). Validade Preditiva de Instrumentos Psicológicos na Avaliação Psicológica de Condutores. Psicologia: Teoria e Pesquisa, 26(4), 695-706.

Teixeira, C. A. (2011). Avaliação Psicológica e sua evolução histórica na Psicologia do Trânsito: A eficácia do roteiro de entrevista na obtenção do apto ou inapto. (Monografia). Centro Universitário de Araras Dr. Edmundo Ulson -UNAR. São Paulo: Araras

Urbina, S. (2007). Fundamentos da Testagem Psicológica. Porto Alegre: Artmed. 
Sobre os autores

Rodolfo Augusto Matteo Ambiel é psicólogo, mestre e doutor em Psicologia na área de concentração em Avaliação Psicológica. Docente da graduação e do Programa de Pós-graduação Stricto Sensu em Psicologia da Universidade São Francisco. rodolfo.ambiel@usf.edu.br

Jocemara Ferreira Mognon é psicóloga, mestre e doutoranda em Psicologia na Universidade São Francisco. jocemognon@gmail.com

Fabiana Mitiko Ishizawa é psicóloga formada pela Universidade São Francisco. fafabiana@orientaconsultoria.com.br

Recebido em: 20/05/2015

Revisado em: 13/08/2015

Aceito em: 21/08/2015 